\title{
Data Governance and Regulation for Sustainable Smart Cities
}

\author{
Johannes Franke ${ }^{1 *}$ and Peter Gailhofer ${ }^{2}$ \\ ${ }^{1}$ Department Environmental Law and Participation, Independent Institute for Environmental Issues (UfU) e.V., Berlin, \\ Germany, ${ }^{2}$ Research Division Environmental Law and Governance, Oeko Institute e.V. - Institute of Applied Ecology, Berlin, \\ Germany
}

It is increasingly understood that data governance is a key variable in the endeavor to design smart cities in such a way that they effectively contribute to achieving sustainability goals and solving environmental problems. However, the question of how different governance options might affect sustainability goals is still open. This article suggests an approach to answering this question from a regulatory perspective. It draws some preliminary lessons from previous regulatory debates, proposes a prospective evaluation of ideal types of data regulation, and finally seeks to outline normative guidelines for social-ecological data governance.

Keywords: data governance, smart city, sustainability, regulation, governance models, governance principles

\section{OPEN ACCESS}

Edited by:

Masaru Yarime,

Hong Kong University of Science and Technology, Hong Kong SAR, China

Reviewed by:

Eduarda Marques Da Costa,

University of Lisbon, Portugal

Dorota Dominika Kamrowska-Zaluska,

Gdansk University of

Technology, Poland

${ }^{*}$ Correspondence:

Johannes Franke

johannes.franke@ufu.de

Specialty section:

This article was submitted to Governance and Cities,

a section of the journal

Frontiers in Sustainable Cities

Received: 24 August 2021 Accepted: 06 December 2021 Published: 24 December 2021

Citation:

Franke J and Gailhofer P (2021) Data Governance and Regulation for Sustainable Smart Cities.

Front. Sustain. Cities 3:763788. doi: 10.3389/frsc.2021.763788

\section{INTRODUCTION}

There is widespread agreement that the city of the future must be both smart and sustainable. The difficult question, however, is how to achieve this goal. While many strategies are being discussed for achieving either "smartness" or sustainability in cities, the links and interdependencies between the two still deserve more attention. For the relationship between smart city concepts (and digitalization in general) and sustainability goals is ambivalent. On the one hand, smart applications promise efficiencies in multiple areas such as water and energy supply, transport and mobility, healthcare, urban planning, or waste management (Angelidou et al., 2018; Bibri, 2019). On the other hand, the smart city concept itself has been called "a branding exercise by big corporations" (Allam and Newman, 2018) and the danger cannot be dismissed that economic imperatives might accelerate unsustainable growth ambitions (Monfaredzadeh and Berardi, 2015; Shelton et al., 2015). This is especially true for environmental considerations that have been underrepresented in smart city concepts compared to economic interests, as research has shown (Ahvenniemi et al., 2017; Haarstad, 2017).

There are different ways to approach the question of how to integrate and implement sustainability goals in smart city development (UN Habitat and Ericson, 2014; Bibri, 2019; Khan et al., 2020). We do so from the viewpoint of data governance (see also Paskaleva et al., 2017; Schieferdecker, 2021), focusing on different regulatory models, tools, and principles. Data is at the heart of any future smart city. Data governance, in turn, decides what data may be collected and used, by whom, in what way, and for which purpose, including, e.g., rights to access and/or use data as well as rules to manage and control the quality and completeness of data. Therefore, decisions on data governance are crucial and set the course for future policy and power structures in the smart city (cf. Gabrys, 2014; Goodman, 2020). Whether and to what extent smart applications will contribute to sustainable cities will not least depend on how the rights and powers regarding relevant data are distributed. The importance of data governance for sustainability in the smart city has been discussed to some extent in the publications cited above. However, there is a lack of 
conceptual approaches that systematically identify and evaluate different regulatory strategies in their implications for sustainability.

Against this background, our paper aims at complementing the ongoing debate on sustainable smart cities with a socioecologically informed perspective on data governance. The guiding question is how to organize access to and use of data in the smart city in order to promote sustainability goals. For this purpose, we will first look at the potentials and risks the smart city paradigm poses to sustainability goals and at how data governance might influence the outcome. We then take a look at the regulatory debate accompanying the privatization and liberalization of infrastructure services in Europe in the 1990s, reflecting on the purpose of and need for regulation in the provision of essential utilities, identifying similarities but also differences compared to the challenge of data governance in the smart city. In a third part, we introduce three ideal-type data governance models as a methodological tool to evaluate the implications of regulatory measures for sustainability goals. We then turn to the values that should guide data governance in the sustainable smart city and propose six regulatory principles before we conclude with an outlook on future tasks and challenges.

\section{THE CHALLENGE: IMPLEMENTING SUSTAINABILITY GOALS IN THE SMART CITY}

In general, digital technologies carry both potentials and risks for sustainability goals. Smart solutions can increase efficiency, thus spare resources and even enable a circular economy, but they also consume lots of energy and may accelerate unsustainable growth dynamics (Liu et al., 2019; Cowls et al., 2021). Assessing the overall environmental effects of smart applications is complex: The increasing direct energy and resource consumption of digital infrastructures, hardware, and software (first-order effects) may be compensated by potential savings due to efficiency gains (second-order effects). Such efficiency gains in turn threaten to be neutralized by so-called systemic, or third-order effects (Hilty et al., 2006; Gailhofer and Franke, 2021). Moreover, particularly in the case of artificial intelligence (AI) or automated decision making (ADM) systems, social and environmental effects can be difficult to grasp as they are mediated by psychological, economic, and social dynamics, but have potentially far-reaching consequences (cf. Gailhofer et al., 2021). For ADM processes shape and even determine human decisions, inducing behavior and ensuring that certain goals are implemented. It is therefore quite plausible to ascribe a regulatory function to ADM systems themselves (Hildebrandt, 2018; Gailhofer and Franke, 2021).

This regulatory function implies that the decision parameters and objectives of ADM are crucial for achieving sustainability goals in the smart city: For instance, AI-based predictive maintenance systems can lead to considerable resource savings by maximizing the lifetime of wear and tear components in complex facilities. Minimizing maintenance costs and minimizing negative environmental effects, however, may represent conflicting objectives in predictive maintenance. In the case of ADM that is oriented toward cost minimization, this may lead to comparatively higher environmental impacts (Carlson and Sakao, 2020). Navigation systems could suggest a slower, but less congested route to avoid traffic jams, or recommend the use of park and ride services. If these systems, however, propose the fastest or most comfortable route for the individual, e.g., to meet presumed or actual customer preferences, this can lead to an overall increase in traffic density and higher $\mathrm{CO}_{2}$ emissions (Rejeski et al., 2018). Other examples show how ADM systems can reinforce environmentally harmful dynamics, even if they are intended to bring about environmental benefits: For instance, smart heating assistants that automatically implement more efficient energy consumption can lead to the non-intended reaction of its users to abandon control over their power usage. This is alleged to lead to excessive energy consumption that frustrates potential efficiency gains (Puntiroli et al., 2019). In more or less autonomously learning ADM systems, data about such an unfavorably influenced user behavior may also flow back into the system as feedback in order to further optimize its functionality. The result might be a highly problematic, selfreinforcing "feedback loop" (cf. Gailhofer and Scherf, 2019; Gailhofer and Franke, 2021).

It is precisely the ability of ADM systems to regulate behavior that can have systemic environmental and/or social effectsfor better or for worse. To date, however, ADM systems have primarily been used by "big tech" to fuel non-sustainable consumption patterns by collecting and analyzing user data in order to influence users through personalized advertising in the commercial interests of third parties (Zuboff, 2019).

Given the importance of the steering objectives, it has been rightly suggested that it is important to integrate sustainability objectives into the basic building blocks of AI (Gebauer, 2019). However, effectively regulating algorithms encounters considerable difficulties resulting, inter alia, from information asymmetries (Krafft et al., 2020). It is not only necessary to understand the complex and indirect effects ADM might have on sustainability. Rather, there is also the fundamental question of how the objectives of ADM are developed in first place-for they are not only generated by targeted training in the interests of the manufacturers or users, but also automatically adapted and further developed by learning ADM systems themselves. Implementing sustainability goals in algorithms would therefore require knowledge not only of the intentions of the developers, but also of the mechanisms of AI learning, which are often difficult to grasp.

Such difficulties indicate the importance of complementary data governance for implementing sustainability goals in the smart city. Regulating the access to and use of data-the fuel of any smart application-is essential for a number of reasons (cf. Gailhofer and Scherf, 2019; Gailhofer and Franke, 2021; Gensch et al., 2021):

- Generally, a sufficient data basis is a necessary condition for effective political decision-making in the smart city. In view of complex socio-ecological problems, political control, and planning require a solid knowledge base in order to 
successfully implement sustainability goals. The authorities' ability to steer "smart" innovations in the common interest as well as to effectively update and to enforce regulatory standards hinges on sufficient access to data.

- Sustainable innovations and applications often rely on access to high-quality data in order to unfold their potential. The availability of such data is therefore crucial for policies which aim at enabling and promoting sustainable solutions.

- Data concentration in the hands of a few private corporations is problematic from a sustainability perspective as well. Private data silos can prevent access to high-value data. Moreover, superior data processing capabilities and economies of network and scale tend to further increase the technological edge of those companies even if there was equal access to their data.

- Finally, the ability to effectively regulate the social and ecological risks posed by $\mathrm{ADM}$ is also conditioned by access to the processed dataset. Code alone is not sufficient to understand how an ADM process works. Rather, ADM systems frequently learn based on data and update their objectives on the basis of constant data feedback to adapt to changing conditions. This points to a substantive dimension of data regulation that is relevant to ADM decisions both at the level of design and in operation: the objectives implemented by ADM systems are very much dependent on which data are used for training or decision optimization. "Wrong" decisions are significantly caused by data bias, i.e., wrong or insufficient data. Particularly in view of the systemic risks of data use, it is possible to speak of a potentially environmentally damaging data bias of ADM. This is because many of the relevant systems develop their steering objectives on the basis of data that may not reflect sustainability aspects (Grafanaki, 2017). Control of complex and dynamic decision systems thus requires an analysis of the data used to train ADM systems. Therefore, regulatory proposals that focus on algorithm control also require corresponding access rights or transparency obligations with respect to the processed data.

Data governance is thus a necessary condition both for effectively implementing sustainability-oriented policies, and for dataeconomic participation of public or private stakeholders in the digital economy.

\section{REGULATORY CHALLENGES REVISITED: THE CASES OF INFRASTRUCTURE REGULATION AND DATA GOVERNANCE}

Before diving into the regulatory challenges of data governance in the smart city, we will take a look at the debate on infrastructure regulation that accompanied the privatizations and liberalizations of the 1990s that strongly affected the provision of public services, particularly at the municipal level. The discussion provides a good starting point for thinking about different models of data governance in the smart city, as it points to general key elements of regulatory concern. This specifically includes the division of tasks and responsibilities between public and private actors, and the implementation of the common interest within those structures via new instruments and institutions.

\section{Infrastructure Regulation: Role, Instruments, and Institutions}

In the 1990s, the privatization and liberalization of infrastructure services such as energy supply, telecommunications, and public (rail and road) transport sparked a debate about the nature and role of "regulation" and the "regulatory state" in Europe and beyond (Majone, 1994, 1997; Loughlin and Scott, 1997; Braithwaite, 1999, 2011). The terms "regulation" and "regulatory state" addressed, on the one hand, the departure from the Keynesian welfare state, in which central utilities had been provided by state and particularly by municipal authorities. On the other hand, the liberalization and privatization of public utilities did not mark a return to a liberal laissez-faire "night watchman state," but was accompanied by new regulatory instruments and institutions (Majone, 1997; Braithwaite, 1999).

The substance of the regulatory task was, and still is, two-fold: On the one hand, regulation seeks to establish market structures and enable effective competition to ensure the efficient provision of services and to promote innovation. Many public utilities are partially natural monopolies because it is not economically feasible to duplicate the underlying infrastructure (e.g., railroads, electricity grid). Therefore, access and price regulation, i.e., legal rights to (co-)use infrastructures at fixed prices, have been established to enable competition of commercial providers on the infrastructure. Also, and particularly in the municipal context, competition for the provision of services is organized in public tenders, granting temporary monopolies, e.g., for operating a city's electricity grid. On the other hand, regulation has to preserve the public interests associated with the provision of basic services, such as social and environmental policy goals. The general interests in a universally available, affordable and environmentally sustainable supply of essential services need to be implemented within those market structures, incentivizing or forcing private companies to take into account the public good. Such instruments include universal public service obligations, i.e., the duty to render basic services to anyone at an affordable price, as well as environmental regulations, e.g., the obligation to purchase electricity primarily from renewable energy sources, and transparency rules for consumer protection. On a municipal level, cities can include social and environmental standards in their tender conditions when they award public contracts for the provision of utilities.

The overall purpose of infrastructure regulation is thus to strike a balance between the interests of commercial actors and the general public by enabling competition and steering it toward socially desirable results. This is reflected in regulatory goals and principles that are usually introduced in the first articles of regulatory laws. For example, Article 3 of the Regulation (EU) 2019/943 on the internal market for electricity names a number of principles, (over-)emphasizing the market principle but also including decarbonization, consumer empowerment, energy security, and transparency. Conflicts between these principles are inevitable and one main reason for the necessity of regulation in 
the first place. More generally, the task to reconcile competition and market logic with the public interest is reflected in the special status that the Treaty on the Functioning of the European Union (TFEU) reserves for "services of general economic interest." Pursuant to Art. 106 (2) TFEU, undertakings entrusted with (i.e., legally obliged to deliver) such services are exempt from certain provisions, particularly of competition law, if and to the extent that the application of such rules would obstruct the performance, in law or in fact, of the particular tasks assigned to them. The provision thus aims to strike a balance between the competition principle and public service objectives. This has been particularly relevant for the application of EU state aid rules. State subsidies are generally prohibited in Art. 107 (1) TFEU because they are presumed to distort the common market. If, however, the subsidy is provided only to ensure the provision of a service of general economic interest, such as providing public transportation in a sparsely populated area, the European Commission will not consider it incompatible with the common market under certain conditions (European Commission., 2012).

Both competition- and common interest-related regulation are ongoing and permanent tasks. The continuous steering of the regulated activity requires detailed knowledge and close involvement on the regulator's part (Majone, 1994, 1999; Loughlin and Scott, 1997). This necessity led to the creation of specialized independent regulatory agencies entrusted with monitoring and regulating the provision of infrastructure services and enforcing regulatory requirements. The idea was that independent regulators would have both greater expertise and be more resistant to the fluctuations of day-to-day politics. Conversely, the agency concept comes with structural accountability and legitimacy problems, as policy-making powers are bestowed on independent regulators that are neither elected nor closely supervised (Majone, 1999).

\section{Data Governance: Challenges Old and New}

Many elements of the discourse about infrastructure regulation are also relevant to the challenge of sustainability-oriented data governance in smart cities. Here as well, we have multiple actors with diverging interests, as illustrated by the "quadruple helix model" that identifies government, academia, industry, and civil society as key players in the development of the smart city (Borkowska and Osborne, 2018). Dealing with market power plays an important role in both cases too-while there are no natural data monopolies in the strict sense, there are factual power structures, supported, and reinforced by economies of network and scale. Moreover, and most importantly in the context at hand, the general trade-off between "free" markets and the public interest is another common feature: Steering innovation in the smart city toward sustainability goals is a challenge similar to preserving the common interest in a privatized utilities sector-in both cases, there is a conflict between sustainability and private competition (Monfaredzadeh and Berardi, 2015). Therefore, existing legal concepts known from infrastructure regulation are also relevant in the context of data governance. This is, for instance, true with regard to "services of general economic interest" (cf. Art. 14, 106 TFEU) that have been introduced above (see section Infrastructure
Regulation: Role, Instruments, and Institutions). This concept can be relevant to data governance in two respects. On the one hand, there is the question of how to deal with data needed for or generated in the provision of a service of general interest. There is an ongoing discussion whether and to what extent such data should be open for re-use by third parties (see below, section Shared and Open Data). On the other hand, the provision of data for certain sustainability goals may itself constitute a service of general interest, where the market does not provide sufficient data (see below, section Proprietary Data Rights). Similar tendencies to privilege certain actors in the common interest can be observed in the proposed provisions on "altruistic data organizations" in the draft EU Data Governance Act (see below, section Civic Data Rights). Finally, reconciling the various interests and goals is - as in the infrastructure sectoran ongoing regulatory task that requires new instruments and institutions. Just as the regulation of public utilities demands more than general trade regulation, the new challenges of ubiquitous computing and datafication go well-beyond data protection law that is particularly ill-equipped for regulating ADM (Krafft et al., 2020).

Despite those parallels, there significant differences between the challenges of infrastructure regulation and data governance. First of all, the underlying developments themselves are fundamentally different: infrastructure privatization and liberalization was initiated on the political level. Existing public sectors were opened up to private competition in the hope of unleashing the innovative power of the market. In the case of smart cities, and digitalization in general, the public sector does not have a leading, let alone monopolistic control over either data or the tools to use it. Rather, it is confronted with an all-encompassing societal transformation which is dominated by private corporations. Moreover, the relationships between different actors have changed and become more complex. Particularly citizens are not simply using smart services and applications but produce and provide, to a considerable degree, the necessary data input, namely as far as it is derived from human behavior (van Zoonen, 2020; Viljoen, 2020). The complexity of actors, accompanied by a diminishing control of public authorities, is already reflected in the broader term "governance," which generally expresses a change toward governing in and through networks, as opposed the more statecentered concept of "regulation" (Braithwaite, 2011). Taking this broader governance perspective is particularly important in the context of the smart city with its multiplicity of actors and their different roles as data producers, data subjects and data users (Grafenstein et al., 2019; Scassa, 2020).

All in all, the general regulatory discussion from the end of the last century offers clues on how to approach the problem of data governance in a structured way. It remains the general task of regulation to implement social and environmental goals in a market environment. However, regulatory instruments and especially institutions have to adapt to the challenges posed by the digital era in general (Cohen, 2016) and smart cities in particular. In the following, we approach this task by first discussing three ideal types of data governance (data property, open data, and civic data rights), their logic of intervention and their potential 
impact on sustainability goals. We then propose principles of data governance that can both illustrate normative conflicts and guide political decision-making.

\section{IDEAL TYPES OF DATA GOVERNANCE AND THEIR IMPLICATIONS FOR SUSTAINABILITY GOALS}

Debates on the regulation of the data economy have been conducted primarily from an economic and competition policy (Sivinski et al., 2017; Haucap, 2019) or civil rights perspective (Janssen et al., 2020; Krafft et al., 2020). However, the difficult question of how different governance alternatives affect sustainability risks or potentials of ADM systems and might thus hamper or promote a socio-ecological transformation has hardly been addressed so far.

Undoubtedly, there are sector- or risk-specific characteristics of ADM in different contexts of application (Krafft et al., 2020), which should be reflected in differentiated data regulatory or governance regimes. In order to better understand the socioecological implications of such choices, however, it is useful to start from ideal types of data governance (cf. Gailhofer and Scherf, 2019; Gailhofer and Franke, 2021). In our view, three ideal types of data regulation can be distinguished:

- First, data is understood as a marketable economic good, subject to proprietary rights of use and exploitation;

- Second, in sharp contrast to exclusive, property-like rights, the concept of shared and open data is promoted;

- Third, ideas based on collective or representative forms of decision-making about the ends and means of data use are gaining traction.

We will examine those three ideal types below, focusing on their sustainability-related opportunities and risks in the context of the smart city. A typology can identify functional mechanisms of regulatory decisions and provide orientation for further considerations regarding the likely effects of regulatory models. Using ideal types as a heuristic, central mechanisms of governance decisions can be identified. While a comprehensive evaluation of data governance models and their impact on sustainability goals cannot be conducted in the framework of this article, this may provide an orientation for further (interdisciplinary and empirical) research.

\section{Proprietary Data Rights}

The first ideal type conceives of data as a marketable economic good. The clearest manifestation of this approach is the idea to create property rights of data producers to "their" data, or the related idea to view data as labor (Arrieta Ibarra et al., 2017). Original rights holders could be the operators of data-generating devices, e.g., owners of a smartphone. While the concept of property rights over data as a regulatory model has been met with skepticism (Drexl, 2016; Stepanov, 2020), this is largely because factual control over data is sufficient to enable data holders to commercialize their data by relying on contract law (Drexl, 2016). Indeed, data are frequently protected as trade secrets under current legislation, and digital applications and technical standards can be designed in such a way that data of different types can be traded or rights of use transferred in return for payment. From a legal perspective, such factual and contractual manifestations of the first ideal type differ considerably from a property right-the economic principles and effects, however, are closely related: data can be clearly assigned and individually utilized in a legally secure manner.

The general idea behind this governance strategy is to establish and optimize data markets. The market mechanism is supposed to facilitate the trading of data and result in its most efficient allocation from a welfare perspective (Zech, 2017). The unambiguous legal assignment of data to a specific rights holder (if necessary supplemented by regulations on transfer, warranty, liability, etc.) is meant to increase the willingness to share data. Through the same mechanism, proprietary data rights are supposed to leverage the innovation potential of digitization for the common good: By improving the conditions for commercializing, i.e., selling and reselling of data or concluding rental or licensing agreements, property rights or technical and/or contractual mechanisms are said to create incentives for increased data production (Zech, 2017). At the same time, paying users of data-driven applications - as data producers - for "their" data would ensure consumers' fair economic participation in the data economy (Arrieta Ibarra et al., 2017).

The idea of leaving the allocation of data to data markets is still quite dominant and factual reality, even in the absence of "market-optimizing" regulatory intervention. However, from a sustainability-oriented perspective, there are fundamental concerns about the welfare-promoting effects of data markets based on proprietary exclusive rights. It stands to reason that data producers will tend to sell their data to those who are willing to pay most. By contrast, public interests or the interests of third parties are likely to play a subordinate role in data markets. The idea of promoting welfare for society as a whole by creating incentives for innovation through private rights of exclusive use and disposal will therefore-as in other marketsproduce negative externalities (Gailhofer and Scherf, 2019). With regard to data quality, one may further question whether data markets can create sufficient incentives for the creation of data for sustainability-oriented applications. This reminds us of the challenges of infrastructure regulation presented above. There as well, the idea of enhancing social welfare by establishing markets was a driving motivation behind the privatization and liberalization movement. However, establishing private markets was by no means sufficient, but had to be accompanied by extensive public-interest related regulation to ensure that social and environmental goals were not neglected by private corporations. In the case of data governance, it is likely that financial incentives would be necessary to promote the sharing and use of data in the public interest, and where markets prove insufficient, players would have to be established and/or subsidized that are legally obliged to provide data for sustainability tasks as a service of general interest within the meaning of Article 106 TFEU (see above, section Infrastructure Regulation: Role, Instruments and Institutions). 
There are more concerns. Strong legal or technical barriers to access and use relevant data could hinder meaningful innovation as well as appropriate regulation of and by AI. Proprietary data rights are likely to reinforce existing market power structures and it is generally doubtful if the innovation- and welfare-enhancing effects of intellectual property rights apply to data as non-rival goods, i.e., goods that can be possessed or consumed by multiple users. Finally, and particularly in the context of smart cities, proprietary data governance strategies are unlikely to be accepted by citizens, as the following example shows.

The pitfalls of a governance strategy betting on exclusive private rights to collect and exploit data can be illustrated by the case of "Sidewalk Toronto" that was originally heralded as a prototype for the sustainable smart city (Goodman and Powles, 2019; Scassa, 2020). In 2017, Google affiliated Sidewalk Labs, in collaboration with the public-held company Waterfront Toronto, set out to develop a prototype smart city in the Waterfront District of Toronto. The development of the project was arcane from the beginning, with relevant proceedings and agreements being kept from public scrutiny (Goodman and Powles, 2019). Especially concerns about the collection, use, and governance of data were raised from the start. A critic testified before Toronto's Executive Committee that "we must think about data infrastructure the way we think about critical physical infrastructure. It cannot be proprietary" (Wylie, 2018). In an attempt to calm public outrage, Sidewalk presented a data governance concept envisioning an "Urban Data Trust" for "urban data," to which no individual should have a proprietary claim. However, the category "urban data" remained opaque and problematic, and the reactive, top-down process of developing the "trust" led to its failure (Scassa, 2020). The Sidewalk Toronto case also confirms fears that private companies will most likely not use exclusive data rights to build a sustainable, but rather a profitable city. In Sidewalk's vision, "smartening" the city meant to attract businesses and to optimize processes according to market logic, while controlling the access to data collected in public spaces-pursuing ideals of platformization, privatization, and domination (Goodman and Powles, 2019). The case thus highlights the dangers that proprietary data governance poses both to democratic governance in the smart city and to sustainable city development. Such a strategy puts private corporations in control, and, without sufficient transparency and accountability mechanisms, there is no reason to believe that the data generated would be used to pursue sustainability goals.

\section{Shared and Open Data}

In explicit distinction to the idea of proprietary data rights, the second ideal type understands digital data as an "infrastructural resource." This approach is based on the recognition that data are non-rival and multifunctional goods that can be utilized multiple times and in a variety of ways (OECD., 2015). In practice, the focus so far has been on providing the widest possible access to data held by public authorities and on improving the conditions for the (voluntary) exchange of data between companies. This is reflected, for instance, in EU legislation, such as the Regulation (EU) 2018/1807 on a framework for the free flow of non-personal data in the European Union and the Directive (EU) 2019/1024 on open data and the re-use of public sector information. The latter focuses on data held by public authorities, but also covers public undertakings that provide certain utility services (e.g., electricity, water, public transport). If those companies share their data with anyone, they generally have to grant the re-use of data under the same conditions to anyone else (Richter, 2020). Data sharing obligations of private companies have also been proposed, either as context- or sector-specific obligations (Drexl, 2016; Richter, 2020), or as general and progressive data-sharing obligations that are triggered if companies reach specific market share levels (Mayer-Schönberger and Ramge, 2018).

The most unrestricted access to and use of data is supposed to lead to a "comedy of the commons" (OECD., 2015): The more data is used, the more social value can be derived from it. Only through freely accessible data can its potential be leveraged to promote digital innovation and thus enable growth, prosperity and improvements, e.g., in the energy, transport, healthcare, or education sectors (OECD., 2015; Mayer-Schönberger and Ramge, 2018). This idea is common to both open data approaches and data sharing obligations of private parties. The welfare potential of open data is often seen primarily in the fact that it should unleash market-oriented innovation potential. General access to mass data on individual preferences is intended to provide market actors with information on a "multitude of needs and priorities" so that these needs can be optimally satisfied (Drexl, 2016; Mayer-Schönberger and Ramge, 2018). Data sharing obligations are thus not intended to create a market for trading data ("data markets"), in contrast to proprietary governance strategies discussed above. Rather, the aim is to optimize markets of all kinds by supplying them with data as comprehensively as possible ("markets through data"), thereby enabling data-driven systems to be better tailored to individual interests (Gailhofer and Scherf, 2019). This idea is similar to network access rights under infrastructure regulation (see above, section Infrastructure Regulation: Role, Instruments, and Institutions), which were also introduced to enable competition and innovation for services "on the infrastructure."

Initially, the assumption that a broad distribution of data can help to realize its societal value seems plausible from a sustainability-oriented perspective as well. The opportunities for scientific, community, or alternative economic actors to develop socio-ecologically meaningful applications also depend on sufficient access to data. Access to high-quality data held by companies or organizations could also counteract problematic data (and therefore power) concentrations. The potentials of improved access to data held by companies are accordingly also highlighted from a sustainability perspective (Corrales-Garay et al., 2020). Finally, data sharing obligations and corresponding access rights might-insofar as they are also granted to the public sector-also provide valuable information regarding the development and enforcement of common interest regulation. At the same time, sharing obligations can reduce private companies' incentives to collect excessive amounts of data (Goodman, 2020).

It is, however, unlikely that those potentials will be realized "automatically" (Janssen et al., 2012). Improving access to data is particularly unlikely to alleviate the problems of the unintended or systemic effects on sustainability described above (see at 
section The Challenge: Implementing Sustainability Goals in the Smart City). If the assumption is valid that such effects often result precisely from the fact that ADM decisions reflect and reinforce problematic behavior patterns of consumers or other market players and thus exhibit a bias to the detriment of public welfare interests, general access to precisely such data does not promise any fundamental improvement in this respect (cf. Janssen et al., 2012). Furthermore, the mere availability of open data is unlikely to solve the issue of market dominance, as big technology firms still have a huge advantage when it comes to analytic capabilities (Goodman, 2020). The hypothesis that additional regulatory measures to just "opening" data are needed is supported by experiences from infrastructure regulation, for instance in the electricity sector: It is not (yet) the general right to non-discriminatory access to the grid that steers the system toward renewable energies, but only the obligation to preferentially buy and feed in electricity from renewable energy sources as, e.g., imposed by section 11 of the German Renewable Energy Act. ${ }^{1}$ With regard to (potential) data sharing obligations of public undertakings or, more broadly, providers of services of general interest, there is also the danger that the provision of data might lead to competitive disadvantages and even an impairment of their ability to provide public services (Richter, 2020). And in some cases, exclusive rights to data use may be necessary for the provision of such services. Under this condition, Art. 12 (2) of Directive (EU) 2019/1024 allows exclusive arrangements regarding data of the public sector, reflecting the general rule in Art. 106 (2) TFEU (see above, section Infrastructure Regulation: Role, Instruments, and Institutions).

Particularly in the context of the smart city, a lot of hope has been put into the potential of open data (cf. Walravens et al., 2014; Ahlgren et al., 2016). Open and shared data initiatives are implemented in numerous cities and in various ways (Ojo et al., 2015; Trindade Neves et al., 2020). Major European cities, such as Amsterdam, Berlin, Copenhagen, London, etc., have established open data platforms where they publish their public data (European Data Portal., 2020). This can be accompanied by data sharing obligations. For example, Barcelona includes clauses in procurement contracts that require service providers to provide all data that may be of public value to the municipality in a machine-readable format (Bass et al., 2018). Research from the mobility sector conducted in nine cities suggests that open data initiatives do have contributed to sustainable innovations (Yadav et al., 2017). However, there is still a lack of comprehensive empirical studies on the overall impact of different open data strategies on sustainability. It is to be welcomed that frameworks for impact assessments evaluating and monitoring the actual effects of open data initiatives on sustainability in the smart city are recently being developed (Trindade Neves et al., 2020).

\footnotetext{
${ }^{1}$ Erneuerbare-Energien-Gesetz of 21 July 2014 (BGBl. I 1066), last amended on 16 July 2021 (BGBl. I S. 3026), available online at https://www.gesetze-im-internet. de/eeg_2014/BJNR106610014.html. An English translation is available at https:// www.bmwi.de/Redaktion/EN/Downloads/renewable-energy-sources-act-2017. pdf\%3F_blob\%3DpublicationFile\%26v\%3D3
}

\section{Civic Data Rights}

A third ideal type of data governance aims to address the blind spots of market-based strategies that strive either for markets in proprietary data (type 1) or for open innovation (type 2). In this concept, data are understood as a "democratic medium" and data rights as a competence to participate and shape public policy, and not just as an individual right to arbitrary use (Fezer, 2018; Delacroix and Lawrence, 2019; Viljoen, 2020). This approach emphasizes the collective, social significance of data processing procedures. In the context of big data and ADM, information about individuals is valuable particularly in relating it to information about others. For the same reason, data can affect the interests of data producers even if they can no longer be related to an individual, i.e., after it has been aggregated or anonymized (Viljoen, 2020). The insights derived from such data can benefit society as a whole, but may also cause risks and damage that cannot be reduced to individual interests. For example, aggregated data on water consumption patterns in a community can be used for profit-maximizing pricing or sold for personalized advertising, but it may also help to develop strategies for reduced water consumption and to efficiently manage drought-based water shortages (Viljoen, 2020). Against this background, the idea of civic data rights demands that citizens should have a say in how and for which purpose their data is employed-it does not focus on access to data, but rather on decisions about data use. Data governance has the function to steer the use of data according to collectively determined normative principles and to balance conflicting interests and values with regard to data use in the process. In contrast to the regulatory proposals discussed above, data governance is thus conceived as an ethical and political challenge, and the decision about its goals is understood as an object of civic deliberation (Fezer, 2018; Gailhofer and Scherf, 2019).

A participatory, democratic approach to data governance calls for the creation of structures, mechanisms and institutions that take into account the collective dimensions of data use by organizing the co-determination of data producers (Viljoen, 2020). It has been suggested, for instance, to establish a data agency as a "representative body of civil society," or "cooperative steering instrument," that exercises citizen rights by, e.g., enacting sector-specific data-related standards of conduct and organizing negotiations between citizens and companies (Fezer, 2018). Other concepts envision a more decentralized structure of different data trusts offering different participatory governance models to choose from (Delacroix and Lawrence, 2019; cf. also Hummel et al., 2018); many other, including technical, solutions are conceivable.

The change in perspective from access rights to participatory decision rights might provide a good chance to implement sustainability goals through data governance. Enabling citizens to make democratic decisions about the use of data they produced could provide public interest actors with privileged or exclusive access to important data sources and thus improve their chances of developing and successfully operating their applications even in the face of private competition. Civic data rights could empower citizens also with regard to ADM 
decisions. As previously discussed (see above, section The Challenge: Implementing Sustainability Goals in the Smart City), the data that is fed to an algorithm determines, to a considerable degree, whether or not sustainability goals will be considered and implemented by ADM. If democratic mechanisms were to be established regarding the question which data might or must be considered by ADM systems in a certain field, citizens would indirectly gain influence on the inclusion of social or ecological values. For instance, citizens might decide that their motion data might only be used for the improvement of transportation services via $\mathrm{ADM}$ if environmental data (such as air pollution) is also incorporated into the algorithm.

Giving citizens the opportunity to actively decide on who can use their data and for what purposes, accompanied by trustworthy technology, processes and actors can also create incentives to share or generate such data. For example, the proposed European Data Governance Act (DGA) suggests a framework for the voluntary registration of entities which collect and process data made available for altruistic purposes (European Commission., 2020). Data altruism is defined in Art. 2 (10) DGA as the permission to use personal or non-personal data for purposes of general interest, such as scientific research or improving public services. Registered data altruism organizations have to fulfill certain transparency requirements (Art. 18 DGA) and they must ensure that data is not used for other purposes than those of general interest they were provided for [Art. 19 (2) DGA]. The possibility of registration is intended to achieve a higher level of trust and thus help to ensure that more data is made available by data subjects and companies to, in turn, achieve higher levels of development and research (European Commission., 2020). At the same time, collecting data for objectives of general interest on the basis of data altruism is exempt from the more stringent requirements otherwise applicable to data sharing services (Art. 14 DGA). This is reminiscent of the privileged status that EU law provides for services of general interest (see above, Infrastructure Regulation: Role, Instruments and Institutions), with the difference that data altruism organizations are envisioned as associations of civil society that deliver their services voluntarily, i.e., without a legal obligation ("entrustment") required by Art. 106 (2) TFEU.

It has frequently and consistently been emphasized that citizen participation is crucial for building sustainable smart cities (Hollands, 2008; Haarstad, 2017; Morozov and Bria, 2018; Goodman and Powles, 2019). It is increasingly realized that this is also and particularly true with respect to data governance (Paskaleva et al., 2017; Scassa, 2020; van Zoonen, 2020). An empirical study conducted under the EU horizon 2020 program has found that smart city initiatives need to engage with relevant stakeholders to collaboratively identify, collect, generate, and use data if they seek to deliver sustainable urban development (Paskaleva et al., 2017). The authors draw the conclusion that the pursuit of sustainability goals calls for more collaborative approaches to data governance. However, existing governance structures are often working toward a topdown use of data, or leave the steering to factual data patterns (van Zoonen, 2020). If the sustainability potentials of the smart city are to be realized, there is a pressing need to develop data governance processes and institutions that enable meaningful citizen participation.

\section{From Ideal to Real Types: Finding the Right Strategy mix}

The criticism regarding the lack of institutionalized citizen participation in data governance is not meant to suggest that civic data rights are a magic bullet solving all problems associated with developing sustainable smart cities. It seems unrealistic and also undesirable to subject all innovative uses of data to collective deliberation, as this is likely to unduly hamper the technological progress, which is not least demanded in the interest of sustainability. Citizen participation and democratic data governance are most important where fundamental decisions are at stake that require a high level of legitimacy.

Overall, however, all three ideal types of data governance described above will likely play a role in developing sustainable smart cities. Open data, for example, is not only relevant to foster innovation but also a key instrument to increase transparency. This can be an important end in itself, especially but not only regarding government data. Data sharing obligations do not have to be applied to any intended data use, but they could be limited to certain public interests. And exclusive data rights might sometimes be necessary to protect public services from the competition of profit-oriented corporations that offer less sustainable services, e.g., if Uber wants to access data from a public transportation company (cf. Richter, 2020). Against this background, civic data rights may not least provide a basis for deciding whether and which data should be open or remain proprietary.

This illustrates that the challenge is not to choose one of the ideal types of data governance but to combine them in a way that best fulfills the fundamental task of any type of regulation: Balancing competing private and public interests. In this complex task, normative principles of data governance can provide orientation.

\section{PRINCIPLES OF DATA GOVERNANCE FOR SUSTAINABLE SMART CITIES}

It is not a coincidence that ethical codes for both smart cities and data governance have mushroomed in the past years. There are a number of declarations that formulate normative guiding ideas for urban development in the smart city (cf. Goodman, 2020). Examples include the "Basque Declaration" 2 that aims "to create productive, sustainable, and resilient cities for a liveable and inclusive Europe" and the "Common Declaration of Principles and Commitments for Sharing Cities"3 setting out 10 principles for sovereign and inclusive smart cities. Additionally, there is an abundance of ethical guidelines on data governance put forward by different political, scientific, business, and civil society actors, particularly in the context of ADM and AI (cf. Jobin et al., 2019).

\footnotetext{
${ }^{2}$ https://sustainablecities.eu/fileadmin/repository/Basque_Declaration/ Basque_Declaration_English.pdf

${ }^{3}$ http://www.sharingcitiesaction.net/wp-content/uploads/2019/05/SharingCities-Declaration-1.pdf
} 
Normative principles play an important role for sustainabilityoriented data governance in the smart city. They can identify, structure, and operationalize different and potentially competing goals and thus support and guide city decision makers in the design and implementation of a sustainable data governance strategy. As we have seen in our recapitulation of infrastructure regulation (see above, section Infrastructure Regulation: Role, Instruments, and Institutions), regulatory principles have been a key component of regulatory frameworks. In the following, we propose six principles of data governance for sustainable smart cities, linking those normative ideas with the regulatory ideal types presented above (section Ideal Types of Data Governance and Their Implications for Sustainability Goals, cf. Gailhofer and Franke, 2021) as well as the UN Sustainable Development Goals (SDGs), particularly SDG 11 "Sustainable Cities and Communities" (UN., 2015).

\section{Individual and Public Data Sovereignty}

Data sovereignty is a colorful term that is used very differently depending on actor and context (Hummel et al., 2018). In a first step, we can subdivide individual and public data sovereignty, with the former addressing the individual, and the latter public authorities, e.g., cities.

Individual data sovereignty refers, in general terms, to the (legal) relationship of an individual to "his" or "her" data. A common and important notion of data sovereignty is privacy, i.e., the right to control and restrict the use of one's personal by others, which has been increasingly come under pressure in the age of big data analysis (De Mooy, 2017). However, broader understandings of individual data sovereignty go well-beyond the protective concept of privacy and particularly include the possibility to share data to promote certain ends (Hummel et al., 2018). Individual data sovereignty is thus closely linked to data governance and regulation: Insofar as data governance assigns data-related decision-making rights to certain actors, it legally establishes and shapes data sovereignty. In that sense, the ideal types presented above each imply different understandings of individual data sovereignty. Proprietary data rights are based on an economic, market-oriented view on data, and data sovereignty. Control over one's own data is expressed in exclusive rights of ownership and the corresponding ability to sell and monetize (but also to just keep) it. The idea of open and shared data has a more complex and ambiguous relationship to data sovereignty. If such a governance strategy simply aims to optimize markets by providing a broad range of behavioral data to a broad range of actors, data sovereignty is diminished to a de facto possibility for citizens to align the product range with their preferences and needs through their consumption behavior. This is in line with the old idea of "consumer sovereignty" (cf. Persky, 1993). However, shared and open data are also promoted with more emancipatory intentions, as a building block of the "knowledge commons" of a democratic city (Morozov and Bria, 2018). This is close to a democratic view on individual data sovereignty also advocated by the idea of civic data rights. Here, data rights are understood as political rights to actively participate in shaping the community by deliberating and (collectively) deciding on the use of data. The idea to democratize data governance by involving citizens in the development of smart city solutions is also in line with SDG 11, which calls for more inclusive and participatory (SDG 11.3) approaches to city management (UN., 2015).

The democratic dimension of individual data sovereignty already points to the (additional) need for public data sovereignty. As we have discussed above (see section Data Governance: Challenges Old and New), a sufficient access to data by public authorities is an essential prerequisite for effectively designing, implementing, and evaluating regulatory instruments. Public data sovereignty thus ensures that democratically legitimized decisions can be made and enforced effectively. As a part of the broader concept of "technological sovereignty" (Morozov and Bria, 2018), public data sovereignty is thus a prerequisite for the ability of cities and municipalities to fulfill their tasks in an increasingly digitalized world.

\section{Regulatory Stewardship}

With a view to the individual and collective implications of digitization, the principle of regulatory stewardship calls for the regulation of data-driven applications and business models by municipal authorities. Cities must not leave the flow of data to itself, but channel it for the common good if the sustainability potential of smart cities is to be realized. Regulatory stewardship thus means taking responsibility and providing a framework for the sustainable use of data in the smart city. This task is relevant to any of the ideal types of data governance described above. It can refer to steering the use of proprietary data, e.g., via financial incentives, to setting conditions of providing and accessing shared and open data, or to establishing institutions and procedures for citizen participation. Regulatory stewardship thus points to the local authorities' role and responsibility in achieving sustainability goals, which has been rightly emphasized in the context of the UN SDGs (UCLG., 2015) and applies to data governance in the smart city as well.

The exercise of regulatory stewardship can take many forms. Sustainable applications and business models can be supported financially, but also, for example, through privileged access to certain data. Especially public procurement offers steering opportunities to cities and municipalities (Bass et al., 2018; Morozov and Bria, 2018). It has already been mentioned that the city of Barcelona includes clauses in their procurement contracts demanding that data of public value must be made available to the city (see above, section Shared and Open Data). Furthermore, the City Council has introduced innovation and ethical clauses (e.g., concerning privacy and open standards) in public tenders to facilitate the access of small enterprises, cooperatives, etc. to public procurement (Morozov and Bria, 2018). Those examples show that cities have their own regulatory instruments even if broader questions, such as data protection and commercial laws, are beyond their legislative competences. Establishing institutional structures for participatory data governance and democratic decision-making on data use also seems possible at the city level.

\section{Data Transparency}

The governance principle of data transparency serves two functions. Firstly, transparency regarding the collection of data 
is intended to satisfy the public interest in information and enable improved control of the administration, or its vendors, in the smart city (information and control function). In this capacity, data transparency can promote public trust by openly communicating to citizens what kind of information is collected in the city and for what purposes (Bass et al., 2018). Transparent decision-making is generally accepted as an important feature of good governance, as reflected in the UN SDG 16.6 to develop "effective, accountable, and transparent institutions" at all levels (UN., 2015). As we have seen in the example of Googleaffiliated Sidewalk Lab's smart city project in Toronto (see above, section Proprietary Data Rights), a lack of transparency can easily lead to public distrust and thus to failure. It should be noted, however, that transparency regarding the collected data alone will often not be sufficient to legitimize ADM. Rather, a broader kind of "algorithmic transparency" is needed, including, inter alia, information on the general goal of ADM systems as well as which (of the collected) data is actually included in which automated decisions (Brauneis and Goodman, 2018).

In addition to its information and control function, data transparency is also intended to promote innovation by making data available for free use (enabling and innovation function). This is the main idea behind the regulatory ideal type II (see above, section Shared and Open Data) and concepts that envision open data as a catalyst for the smart city as an "innovation platform" (Walravens et al., 2014). We have already discussed the ambiguity of this concept and potential pitfalls of purely "open" innovation for social and ecological goals. Nonetheless, open data can enable new insights, sustainable innovations and promote opportunities for citizen participation and thus be an important building block for smart and sustainable cities.

\section{Data Solidarity}

The principle of data solidarity has different dimensions as well. First, it points to the need to share data held by citizens and businesses in order to solve societal problems. Beyond mere transparency requirements, data solidarity thus calls for sharing and providing (privately held) data to promote the common interest. Data solidarity can be exercised in different ways, e.g., through individual data donations (Hummel et al., 2018) or data cooperatives (Micheli et al., 2020), and it may also be enforced through (statutory or contractual) sharing obligations (see above, section Shared and Open Data).

Data solidarity furthermore calls for an equal distribution of the social benefits of digitization. This includes reducing information asymmetries as well as avoiding discrimination and de-solidarization. It is thus directly linked to SDG 11 that expressly aims at building "inclusive" cities that take into account the needs of vulnerable groups in particular, as well as to the more general goal (SDG 10) to reduce inequality (UN., 2015). Smart cities must therefore actively counteract the digital divide in urban society (Goodman, 2020; Shin et al., 2021) and provide targeted support for vulnerable groups to ensure equal participation in data-driven innovations.

\section{Data Sufficiency}

Finally, the principle of data sufficiency opposes an excessive collection and processing of data, both from an ecological and a privacy perspective. As part of the broader concept of digital sufficiency, it addresses the energy and resource consumption of data-driven applications (cf. Lange and Santarius, 2018). There is a need for an ecological cost-benefit analysis of data-driven applications that is not (only) aimed at efficiency, but (also) at sufficiency. Such an analysis critically questions the extent to which data collection and analysis are ecologically useful considering their consumption of energy and resources, in line with the general endeavor to decouple economic growth from environmental harm, as stipulated in SDG 8.4 (UN., 2015). From a privacy perspective, the principle of data sufficiency demands that the collection and processing of personal data is limited to what is necessary and proportional. This is reflected in the principle of "data minimization" laid down in Art. 6 (1) lit.c GDPR.

\section{Overlaps, Conflicts, and Implementation}

These proposed principles of data governance are neither completely independent of each other nor can they all be fully implemented in their purest form. On the one hand, there are some overlaps and synergies. For instance, overcoming the digital divide (in line with the principle of data solidarity) is necessary to enable meaningful decision-rights for all citizens, thus promoting their individual data sovereignty. Public data sovereignty is an important prerequisite for the exercise of regulatory stewardship, and so on. On the other hand, there are inherent conflicts between different principles. For example, the ideas of data transparency and data sufficiency can contradict each other, as the former demands a high level of availability and the latter a limited collection and use of data. Similarly, government control of data flows (data stewardship) may collide with individual data sovereignty. It is important to understand that such conflicts and contradictions are not a weakness, but an essential part of any set of principles and the normative guidance it can provide.

The proposed principles may thus inform political decisionmaking both between and within the ideal types of data governance described above. A particular governance type might be closer to some principles than to others, such as the idea of shared and open data will likely promote data transparency but not data sufficiency. The challenge is therefore to combine the strengths of different governance types and to design regulatory instruments in such a way that the weaknesses of each strategy are avoided. Financial incentives to provide (data for) sustainable solutions, transparency requirements, and/or the prohibition of certain practices might alleviate some shortcomings of proprietary data rights. In the context of shared and open data, the access to and use of data can be regulated and made subject to certain conditions that may privilege some use cases and prohibit others. And for the exercise of civic data rights, institutions and procedures have to be established that ensure meaningful participation, accompanied by (information) policies that enable and motivate citizens to take part in the shaping of the city. 


\section{CONCLUSION}

Data governance is a key component in the development of sustainable smart cities. Rules regarding the collection of, access to and control over the use of data will have far-reaching implications for who is in power and which goals are pursued in a digitalized urban environment. The complexity of actors and the necessity to reconcile competing economic, ecologic, and social interests and values call for a regulatory, or governance, framework. The earlier debate on infrastructure regulation following the privatization and liberalization of public utilities has shown that complex regulatory structures, instruments, and institutions are needed to balance private (commercial) and public (sustainability) interests. This is even more true in the context of the smart city, where private corporations often have superior skills and knowledge and ADM systems can influence human behavior in various ways and for better or worse. In this environment, data governance is a key factor for regulatory capabilities of public authorities, market opportunities for innovative enterprises, and citizens' capacities for participation.

In this article, we have tried to structure the debate on data governance in order to provide some orientation in the maze of different policy proposals. For this purpose, we have identified three ideal types of data governance that are currently being discussed and implemented and evaluated them from a sustainability-oriented perspective. We have argued that marketoriented approaches, whether they are based on the trading of proprietary data or on the free use of open data, are unlikely to stimulate sustainable innovation on their own and require extensive complementary regulatory intervention. The concept of civic data rights is a promising idea to structurally integrate competing goals and interests into governance decisions but is dependent on the development of new institutional frameworks. We believe that developing and implementing such frameworks holds particular promise to further urban sustainability. The UN SDG 11 calls for making cities "more inclusive, safe, resilient, and sustainable." The concept of inclusivity already suggests that including citizens in city governance is crucial, which is further reflected in SDG target 11.3 to "enhance inclusive and sustainable urbanization and capacity for participatory (...)

\section{REFERENCES}

Ahlgren, B., Hidell, M., and Ngai, E. C.-H. (2016). Internet-of-things for smart cities: interoperability and open data. IEEE Internet Comput. 20, 52-56. doi: 10.1109/MIC.2016.124

Ahvenniemi, H., Huovila, A., Pinto-Seppä, I., and Airaksinen, M. (2017). What are the differences between sustainable and smart cities? Cities 60, 234-245. doi: 10.1016/j.cities.2016.09.009

Allam, Z., and Newman, P. (2018). Redefining the smart city: culture, metabolism and governance. Smart Cities 1, 4-25. doi: 10.3390/smartcities 1010 002

Angelidou, M., Psaltoglou, A., Komninos, N., Kakderi, C., Tsarchopoulos, P., and Panori, A. (2018). Enhancing sustainable urban development through smart city applications. J. Sci. Technol. Policy Manage. 9, 146-169. doi: 10.1108/JSTPM-05-2017-0016

Arrieta Ibarra, I., Goff, L., Jimenez Hernández, D., Lanier, J., and Weyl, E. G. (2017). "Should we treat data as labour? Moving beyond "free"," in human settlement planning and management" (UN., 2015). Furthermore, the general task of "sustainable development" can be described as achieving a balance between economic, social, and environmental goals, and to resolve inevitable conflicts between those goals (Vaidya and Chatterji, 2020). Citizens should be involved in this balancing of competing interests to legitimize policy decisions concerning their living environment. In the context of the smart city, this particularly includes decisions on data governance, i.e., who can use what data for which purposes.

While citizen participation has a great and (yet) largely untapped potential in data governance in the smart city, a combination of different governance strategies and instruments will most likely be necessary. Finding the right policy mix is a complex task that can be guided by the (sometimes conflicting) normative principles of individual and public data sovereignty, regulatory stewardship, data transparency, data solidarity, and data sufficiency. The thoughts on regulatory ideal types and principles of data governance presented in this article propose a structural framework for further discussions and may provide a stimulation for further, ideally inter- and transdisciplinary investigations and empirical research into sustainability-oriented data governance.

\section{DATA AVAILABILITY STATEMENT}

The original contributions presented in the study are included in the article/supplementary material, further inquiries can be directed to the corresponding author/s.

\section{AUTHOR CONTRIBUTIONS}

All authors listed have made a substantial, direct, and intellectual contribution to the work and approved it for publication.

\section{FUNDING}

This article is in part based on research in the project Data Governance and Regulation for a sustainable Berlin, funded by the City of Berlin and carried out by the research association Ecornet. The authors are part of the research team.
American Economic Association Papers and Proceedings, Vol. 108, (Nashville, TN: American Economic Association), 38-42. doi: 10.1257/pandp.20181003

Bass, T., Sutherland, E., and Symons, T. (2018). Reclaiming the Smart City: Personal Data, Trust and the New Commons. Available online at: https://media.nesta.org. uk/documents/DECODE-2018_report-smart-cities.pdf (accessed December 13, 2021).

Bibri, S. E. (2019). The anatomy of the data-driven smart sustainable city: instrumentation, datafication, computerization and related applications. J. Big Data 6, 59. doi: 10.1186/s40537-019-0221-4

Borkowska, K., and Osborne, M. (2018). Locating the fourth helix: rethinking the role of civil society in developing smart learning cities. Int. Rev. Educ. 64, 355-372. doi: 10.1007/s11159-018-9723-0

Braithwaite, J. (1999). Accountability and Governance under the New Regulatory State. Aust. J. Publ. Admin. 58, 90-97. doi: 10.1111/1467-8500.00077

Braithwaite, J. (2011). "The regulatory state?," in The Oxford Handbook of Political Science, ed R. E. Goodin (Oxford: Oxford University Press). doi: 10.1093/oxfordhb/9780199604456.013.0011 
Brauneis, R., and Goodman, E. P. (2018). Algorithmic transparency for the smart city. Yale J. Law Technol. 20, 103-176. doi: 10.31228/osf.io/fjhw8

Carlson, A., and Sakao, T. (2020). Environmental assessment of consequences from predictive maintenance with artificial intelligence techniques: importance of the system boundary. Proc. CIRP 90, 171-175. doi: 10.1016/j.procir.2020.01.093

Cohen, J. E. (2016). The regulatory state in the information age. Theoret. Inqui. Law. 17, 369-414.

Corrales-Garay, D., Mora-Valentín, E.-M., and Ortiz-de-Urbina-Criado, M. (2020). Entrepreneurship through open data: an opportunity for sustainable development. Sustainability 12, 5148. doi: 10.3390/su12125148

Cowls, J., Tsamados, A., Taddeo, M., and Floridi, L. (2021). The AI gambit: leveraging artificial intelligence to combat climate change-opportunities, challenges, and recommendations. AI Soc. doi: 10.1007/s00146-021-01294-x

De Mooy, M. (2017). Rethinking Privacy Self-Management and Data Sovereignty in the Age of Big Data. Considerations for Future Policy Regimes in the United States and the European Union. Bertelsmann Foundation, Center for Democracy and Technology. ed Bertelsmann Stiftung. Availabe online at: https://www.bertelsmann-stiftung.de/de/publikationen/publikation/did/ rethinking-privacy-self-management-and-data-sovereignty-in-the-age- ofbig-data (accessed December 13, 2021).

Delacroix, S., and Lawrence, N. D. (2019). Bottom-up data trusts: disturbing the 'one size fits all' approach to data governance. Int. Data Priv. Law 9, 236-252. doi: 10.1093/idpl/ipz014

Drexl, J. (2016). Designing Competitive Markets for Industrial Data - Between Propertisation and Access. Max Planck Institute for Innovation and Competition Research Paper No. 16-13. Availabe online at: https://papers.ssrn. com/sol3/papers.cfm?abstract_id=2862975 (accessed December 13, 2021).

European Commission. (2012). Commission Decision of 20 December 2011 on the Application of Article 106 (2) of the Treaty on the Functioning of the European Union to State Aid in the Form of Public Service Compensation Granted to Certain Undertakings Entrusted With the Operation of Services of General Economic Interest. Availabe online at: https://eur-lex.europa.eu/legal-content/ en/ALL/?uri=CELEX\%3A32012D0021 (accessed December 13, 2021).

European Commission. (2020). Proposal for a Regulation of the European Parliament and of the Council on European data governance (Data Governance Act), $\operatorname{COM}(2020) 767$ final. Availabe online at: https://eur-lex.europa.eu/ legal-content/EN/TXT/?uri=CELEX\%3A52020PC0767 (accessed December 13, 2021).

European Data Portal. (2020). Analytical Report 4: Open Data in Cities. Availabe online at: https://data.europa.eu/sites/default/files/edp_analytical_report_ n4_-_open_data_in_cities_v1.0_final.pdf (accessed December 13, 2021).

Fezer, K.-H. (2018). Repräsentatives Dateneigentum, Ein Zivilgesellschaftliches Bürgerrecht. Studie im Auftrag der Konrad-Adenauer-Stiftung e. V. zum Thema "Einführung Eines Besonderen Rechts an Daten". Availabe online at: https://www.kas.de/de/einzeltitel/-/content/repraesentativesdateneigentum (accessed December 13, 2021).

Gabrys, J. (2014). Programming environments: environmentality and citizen sensing in the smart city Environ. Plann. D Soc. Space 32, 30-48. doi: $10.1068 / \mathrm{d} 16812$

Gailhofer, P., and Franke, J. (2021). Datenregulierung als sozial-ökologische Weichenstellung. Z. Umwel. 2021, 532-540.

Gailhofer, P., Herold, A., Schemmel, J. P., Scherf, C. S., Urrutia, C., Köhler, A., et al. (2021). The Role of Artificial Intelligence in the European Green Deal, Study for the Special Committee on Artificial Intelligence in a Digital Age (AIDA), Policy Department for Economic, Scientific and Quality of Life Policies. Luxembourg: European Parliament.

Gailhofer, P., and Scherf, C.-S. (2019). Regulierung der Datenökonomie. Ansätze Einer Ökologischen Positionierung. Öko-Institut Working Paper. Availabe online at: https://www.oeko.de/fileadmin/oekodoc/WP-Datenregulierung.pdf (accessed December 13, 2021).

Gebauer, J. (2019). Roboter als klimaschützer. Z. Umwel. 10, 513-514. Available online at: https://www.zur.nomos.de/fileadmin/zur/doc/Standpunkt_ZUR_ 19_10.pdf

Gensch, C.-O., Behrens, F., Braungardt, S., Gailhofer, P., Gröger, J., Sutter, J., et al. (2021). Deutschland auf Dem Weg zur Klimaneutralität: Welche Chancen und Risiken Ergeben Sich Durch die Digitalisierung? Abschlussbericht zum Vorhaben 1000333379 der KfW.
Goodman, E. P. (2020). "Smart city ethics: how "smart" challenges democratic governance," in The Oxford Handbook of Ethics of AI, eds D. Dubber, F. Pasquale, and S. Das (Oxford: Oxford University Press). 823-840. doi: 10.1093/oxfordhb/9780190067397.013.53

Goodman., E. P., and Powles, J. (2019). Urbanism under google: lessons from sidewalk Toronto. Fordham Law Rev. 88, 457-498. doi: 10.2139/ssrn.3390610

Grafanaki, S. (2017). Autonomy challenges in the age of big data. Fordham Intell. Prop. Med. Entertain. Law. J. 27, 803-868. Available online at: https://ir.lawnet. fordham.edu/iplj/vol27/iss $4 / 3$ /

Grafenstein, M., Wernick, A., and Olk, C. (2019). Data governance: enhancing innovation and protecting against its risks. Intereconomics 54, 228-232. doi: 10.1007/s10272-019-0829-9

Haarstad, H. (2017). Constructing the sustainable city: examining the role of sustainability in the "smart city" discourse. J. Environ. Policy Plann. 19, 423-437. doi: 10.1080/1523908X.2016.1245610

Haucap, J. (2019). Competition and competition policy in a data-driven economy. Intereconomics 54, 201-208. doi: 10.1007/s10272-019-0825-0

Hildebrandt, M. (2018). Algorithmic regulation and the rule of law. Philos. Trans. Roy. Soc. A 376, 20170355. doi: 10.1098/rsta.2017. 0355

Hilty, L. M., Arnfalk, P., Erdmann, L., Goodman, J., Lehmann, M., and Wäger, P. (2006). The relevance of information and communication technologies for environmental sustainability - a prospective simulation study. Environ. Modell. Softw. 21, 1618-1629. doi: 10.1016/j.envsoft.2006.05.007

Hollands, R. (2008). Will the real smart city please stand up? City 12, 303-320. doi: $10.1080 / 13604810802479126$

Hummel, P., Braun, M., Augsberg, S., and Dabrock, P. (2018). Sovereignty and data sharing. ITU J. ICT Discov. 1. Available online at: http://handle.itu.int/11.1002/ pub/8129f4b2-en (accessed December 13, 2021).

Janssen, M., Brous, P., Estevez, E., Soares Barbosa, L., and Janowski, T. (2020). Data governance: organizing data for trustworthy artificial intelligence. Gov. Inform. Quar. 37, 101493. doi: 10.1016/j.giq.2020.101493

Janssen, M., Charalabidis, Y., and Zuiderwijk, A. (2012). Benefits, adoption barriers and myths of open data and open government. Inform. Syst. Manage. 29, 258-268. doi: $10.1080 / 10580530.2012 .716740$

Jobin, A., Ienca, M., and Vayena, E. (2019). The global landscape of AI ethics guidelines. Nat. Mach. Intell. 1, 389-399. doi: 10.1038/s42256-019-00 88-2

Khan, H. H., Malik, M. N., Zafar, R., et al. (2020). Challenges for sustainable smart city development: a conceptual framework. Sustain. Dev. 28, 1507-1518. doi: $10.1002 /$ sd.2090

Krafft, T., Zweig, K., and König, P. (2020). How to regulate algorithmic decisionmaking: a framework of regulatory requirements for different applications. Regul. Govern. doi: 10.1111/rego.12369

Lange, S., Santarius, T. (2018): Smarte grüne Welt?. Munich: Oekom. Available online at: https://www.oekom.de/buch/smarte-gruene-welt-9783962380205 (accessed December 13, 2021).

Liu, R., Gailhofer, P., Gensch, C.-O., Köhler, A., and Wolff, F. (2019). Impacts of the Digital Transformation on the Environment and Sustainability. Issue Paper under Task 3 from the "Service Contract on Future EU Environment Policy". Available online at: https://ec.europa.eu/environment/enveco/resource_ efficiency/pdf/studies/issue_paper_digital_transformation_20191220_final.pdf (accessed December 13, 2021).

Loughlin, M., and Scott, C. (1997). "The regulatory state," in Developments in British Politics Vol. 5, P. Dunleavy, A. Gamble, I. Holiday, and G. Peele (London: Palgrave) 205-219.

Majone, G. (1994). The rise of the regulatory state in Europe. West Eur. Polit. 17, 77-101. doi: 10.1080/01402389408425031

Majone, G. (1997). From the positive to the regulatory state: causes and consequences of changes in the mode of governance. J. Publ. Policy 17, 262-275. doi: 10.1080/13501769709696342

Majone, G. (1999). The regulatory state and its legitimacy problems. West Eur. Polit. 22, 1-24. doi: 10.1080/01402389908425284

Mayer-Schönberger, V., and Ramge, T. (2018). Reinventing Capitalism in the Age of Big Data. New York. NY: Basic Books.

Micheli, M., Ponti, M., Craglia, M., and Berti Suman, A. (2020). Emerging models of data governance in the age of datafication. Big Data Soc. 7, JRC117363. doi: $10.1177 / 2053951720948087$ 
Monfaredzadeh, T., and Berardi, U. (2015). Beneath the smart city: dichotomy between sustainability and competitiveness. Int. J. Sustain. Build. Technol. Urb. Dev. 6, 140-156. doi: 10.1080/2093761X.2015.1057875

Morozov, E., and Bria, F. (2018). Rethinking the Smart City: Democratizing Urban Technology. New York, NY: Rosa Luxemburg Stiftung. Available online at: https://sachsen.rosalux.de/fileadmin/rls_uploads/pdfs/sonst_ publikationen/rethinking_the_smart_city.pdf (accessed December 13, 2021).

OECD. (2015). Data-Driven Innovation, Big Data for Growth and WellBeing. Available online at: https://www.oecd.org/sti/data-driven-innovation9789264229358-en.htm (accessed December 13, 2021).

Ojo, A., Curry, E., and Zeleti, F. A. (2015). "A tale of open data innovations in five smart cities," in 48th Hawaii International Conference on System Sciences (Kauai), 2326-2335. doi: 10.1109/HICSS.20 15.280

Paskaleva, K., Evans, J., Martin, C., Linjordet, T., Yang, D., and Karvonen, A. (2017). Data governance in the sustainable smart city. Informatics 4, 41. doi: 10.3390/informatics4040041

Persky, J. (1993). Retrospectives - consumer sovereignty. J. Econ. Perspect. 7, 182-191. doi: $10.1257 /$ jep.7.1.183

Puntiroli, M., Bezencon, V., Pino, G., and Lemarie, L. (2019). "When technology backfires and when it succeeds: positive and negative effects of eco-efficient automation on consumers' choices," in NA - Advances in Consumer Research, Vol. 47, eds R. Bagchi, L. Block, and L. Lee (Duluth, MN: Association for Consumer Research), 817-818.

Rejeski, D., Reynolds, L., and Wright, S. (2018). When Software Rules: Rule of Law in the Age of Artificial Intelligence. Available online at: https:/www.eli.org/ sites/default/files/eli-pubs/when-software-rules-web.pdf (accessed December 13, 2021).

Richter, H. (2020). Exposing the Public Interest Dimension of the Digital Single Market: Public Undertakings as a Model for Regulating Data Sharing. Max Planck Institute for Innovation and Competition Research Paper No. 20-03. doi: $10.2139 /$ ssrn. 3565762

Scassa, T. (2020). Designing data governance for data sharing: lessons from sidewalk Toronto. Technol. Regul. 2020, 44-56. Available online at: https:// papers.ssrn.com/sol3/papers.cfm?abstract_id=3722204

Schieferdecker, I. (2021). Urbane datenräume und digitale gemeingüterinstrumente für open government und mehr, in Praxishandbuch Forschungsdatenmanagement, eds M. Putnings, H. Neuroth, and J. Neumann (Berlin: De Gruyter), 175-195. doi: 10.1515/9783110657807-010

Shelton, T., Zook, M., and Wiig, A. (2015). The "actually existing smart city". Cambrid. J. Reg. Econ. Soc. 8, 13-25. doi: 10.1093/cjres/rsu026

Shin, S.-Y., Kim, D., and Chun, S. A. (2021). Digital divide in advanced smart city innovations. Sustainability 13, 4076. doi: 10.3390/su13074076

Sivinski, G., Okuliar, A., and Kjolbye, L. (2017). Is big data a big deal? A competition law approach to big data. Eur. Compet. J. 13, 199-227. doi: $10.1080 / 17441056.2017 .1362866$

Stepanov, I. (2020). Introducing a property right over data in the EU: the data producer's right - an evaluation. Int. Rev. Law Comput. Technol. 34, 65-86. doi: 10.1080/13600869.2019.1631621

Trindade Neves, F., de Castro Neto, M., and Aparicio, M. (2020). The impacts of open data initiatives on smart cities: a framework for evaluation and monitoring. Cities 106, 102860. doi: 10.1016/j.cities.2020.102860

UCLG. (2015). The Sustainable Development Goals - What Local Governments
Need to Know. Available online at: https://www.citiesalliance.org/sites/default/ files/publications/UCLG\%202015\%20The_sdgs_what_localgov_need_to_ know.pdf

UN Habitat and Ericson (2014), The Role of IDCT in the proposed Urban Sustainable Development Goal and the New Urban Agenda. Available online at: https://unhabitat.org/the-role-of-ict-in-the-proposed-urban-sustainabledevelopment-goal-and-the-new-urban-agenda/ (accessed December 13, 2021).

UN. (2015). Resolution Adopted by the General Assembly on 25 September 2015 70/1. Transforming our World: The 2030 Agenda for Sustainable Development. Available online at: https://www.un.org/en/development/desa/population/ migration/generalassembly/docs/globalcompact/A_RES_70_1_E.pdf

Vaidya, H., and Chatterji, T. (2020). SDG 11 "Sustainable cities and communities," in Actioning the Global Goals for Local Impact - Towards Sustainability Science, Policy, Education and Practice, eds I. B. Franco, T. Chatterji, E. Derbyshire, and J. Tracey (Singapore: Springer), 173-185. doi: 10.1007/978-981-32-9927-6_12

van Zoonen, L. (2020). Data governance and citizen participation in the digital welfare state. Data Policy 2, e10. doi: 10.1017/dap.2020.10

Viljoen, S. (2020). Democratic data: a relational theory for data governance Yale Law J. 131, 573-654. doi: 10.2139/ssrn.3727562

Walravens, N., Breuer, J., and Ballon, P. (2014). Open data as a catalyst for the smart City as a local innovation platform. Commun. Strat. 1, 15-33. Available online at: https://papers.ssrn.com/sol3/papers.cfm?abstract_id=2636315

Wylie, B. (2018). My Deputation to Toronto's Executive Committee on Sidewalk Toronto. Availabe online at: https://medium.com/@biancawylie/mydeputation-totorontos-executive-committee-on-sidewalk-toronto-jan24-2018-ee25785bc44e (accessed January 25, 2018).

Yadav, P., Hassan, S., Ojo, A., and Curry, E. (2017). "The role of open data in driving sustainable mobility in nine smart cities," in European Conference on Information Systems, ECIS 2017 (Guimaraes), 1248-1263.

Zech, H. (2017). Building a European data economy - the European Commission's proposal for a data producer's right. Z. Geist. Eigen. Intell. Prop. J. 9, 317-330. doi: 10.1628/186723717X15069451170892

Zuboff, S. (2019). The Age of Surveillance Capitalism: The Fight for the Future at the New Frontier of Power. London: Profile Books.

Conflict of Interest: The authors declare that the research was conducted in the absence of any commercial or financial relationships that could be construed as a potential conflict of interest.

Publisher's Note: All claims expressed in this article are solely those of the authors and do not necessarily represent those of their affiliated organizations, or those of the publisher, the editors and the reviewers. Any product that may be evaluated in this article, or claim that may be made by its manufacturer, is not guaranteed or endorsed by the publisher.

Copyright $\odot 2021$ Franke and Gailhofer. This is an open-access article distributed under the terms of the Creative Commons Attribution License (CC BY). The use, distribution or reproduction in other forums is permitted, provided the original author(s) and the copyright owner(s) are credited and that the original publication in this journal is cited, in accordance with accepted academic practice. No use, distribution or reproduction is permitted which does not comply with these terms. 